Article

\title{
An Approach for Rapid Assessment of Seismic Hazards in Turkey by Continuous GPS Data
}

\author{
Haluk Ozener ${ }^{1,2, *}$, Asli Dogru ${ }^{2}$ and Ahmet Unlutepe ${ }^{3}$ \\ ${ }^{1}$ Istanbul Technical University, Department of Geodesy and Photogrammetry Engineering, Surveying \\ Technique Division, Maslak, 34469, Istanbul, Turkey \\ 2 Bogazici University, Kandilli Observatory and Earthquake Research Institute, Geodesy Department, \\ Cengelkoy, 34680, Istanbul, Turkey; E-Mail: asli.dogru@boun.edu.tr \\ ${ }^{3}$ Strabag Inc., Niagara Tunnel Facility Project, 2520 Stanley Avenue, Niagara Falls, ON L2E6S4, \\ Canada; E-mail: ahunlu@yahoo.com
}

* Author to whom correspondence should be addressed; E-mail: haluk.ozener@itu.edu.tr; ozener@boun.edu.tr; Tel.: +90 21651632 64; Fax: +90 2163320241

Received: 29 December 2008; in revised form: 15 January 2009 / Accepted: 15 January 2009 / Published: 20 January 2009

\begin{abstract}
The Earth is being monitored every day by all kinds of sensors. This leads an overflow of data in all branches of science nowadays, especially in Earth Sciences. Data storage and data processing are the problems to be solved by current technologies, as well as by those accessing and analyzing these large data sources. Once solutions have been created for collecting, storing and accessing data, then the challenge becomes how to effectively share data, applications and processing resources across many locations. The Global Positioning System (GPS) sensors are being used as geodetic instruments to precisely detect crustal motion in the Earth's surface. Rapid access to data provided by GPS sensors is becoming increasingly important for deformation monitoring and rapid hazard assessments. Today, reliable and fast collection and distribution of data is a challenge and advances in Internet technologies have made it easier to provide the needed data. This study describes a system which will be able to generate strain maps using data from continuous GPS stations for seismic hazard analysis. Strain rates are a key factor in seismic hazard analyses. Turkey is a country prone to earthquakes with a long history of seismic hazards and disasters. This situation has resulted in the studies by Earth scientists that focus on Turkey in order to improve their understanding of the Earth's crust structure and seismic hazards. Nevertheless, the construction of models, data access and analysis are
\end{abstract}


often not fast as expected, but the combination of Internet technologies with continuous GPS sensors can be a solution to overcome this problem. This system would have the potential to answer many important questions to assess seismic hazards such as how much stretching, squashing and shearing is taking place in different parts of Turkey, and how do velocities change from place to place? Seismic hazard estimation is the most effective way to reduce earthquake losses. It is clear that reliability of data and on-line services will support the preparation of strategies for disaster management and planning to cope with hazards.

Keywords: GPS; deformation monitoring; strain analysis; seismic hazard; sensor web.

\section{Introduction}

Turkey is an earthquake-prone country has a long history of natural hazards and disasters. Approximately 96 percent of the land containing 66 percent of the active faults is affected by earthquake hazards and 98 percent of its population lives in these regions. The Marmara region includes 11 large cities with populations of more than one million and 75 percent of the country's largest industrial complexes. Scientific understanding of earthquakes is vital for assessing earthquake hazards, and earthquake hazard estimation is the most effective way for Earth scientists to reduce earthquake losses. Therefore the investigation of crustal strain, which means long-term prediction of earthquake hazards, can provide strategies for effective earthquake risk reduction.

In 1999, the Kocaeli earthquake which struck the densely populated industrial heartland of Turkey, was responsible for 20,000 deaths and 45,000 injuries and displaced more than 300,000 people. According to the UNDP (The United Nations Development Program) [1], Turkey is the third country in terms of deaths related to the earthquakes. Earthquake hazards cause an enormous cost to the society in terms of loss of life and property. It is clear that substantial savings could be made with better understanding of the events and improved prediction, which can help to mitigate the risks. In a narrow sense, an earthquake is a sudden failure process, but in a broad sense, it is a long-term complex stress accumulation and release process occurring in the Earth's crust. Therefore, scientific understanding of earthquakes is vital. As the population increases, urban development and construction works expand on areas susceptible to earthquakes. By means of a greater understanding of the causes and effects of earthquakes, it may be possible to reduce the damage and loss of life resulting from of these destructive phenomena.

This study describes a systematic approach to solving the problems related to converting data to information in earthquake research as quickly and effectively as possible. The rapid analysis of the huge amount of raw data gathered by the sensors that are increasing in number, especially in the scientific area of Space Geodesy, has gaining crucial importance for Earth scientists. In this case, if the needs for rapid analysis, interpretation and presentation are secured then the end results will ensure the high temporal resolution needed for accurate interpretation of earthquake phenomena, and this in turn should lead to mitigation of earthquake damage. 


\section{Continuous GPS Sensors}

Turkey has a GPS network named Marmara Continuous GPS Network (MAGNET) [2] collaborated by TUBITAK-MRC (Turkish Scientific and Technological Research Council - Marmara Research Center), MIT (Massachusetts Institute of Technology), ITU (Istanbul Technical University), GCM (General Command of Mapping) and Geodesy Department of KOERI (Kandilli Observatory and Earthquake Research Institute) of Bogazici University (Figure 1). The network currently has 21 permanent GPS stations operated by TUBITAK-MRC. GPS sensors are observing 24 hours at these points for deformation monitoring.

Figure 1. Location of GPS Sensors of MAGNET in Marmara Region (map produced by TUBITAK-MRC). Red lines indicate fault lines in the region.

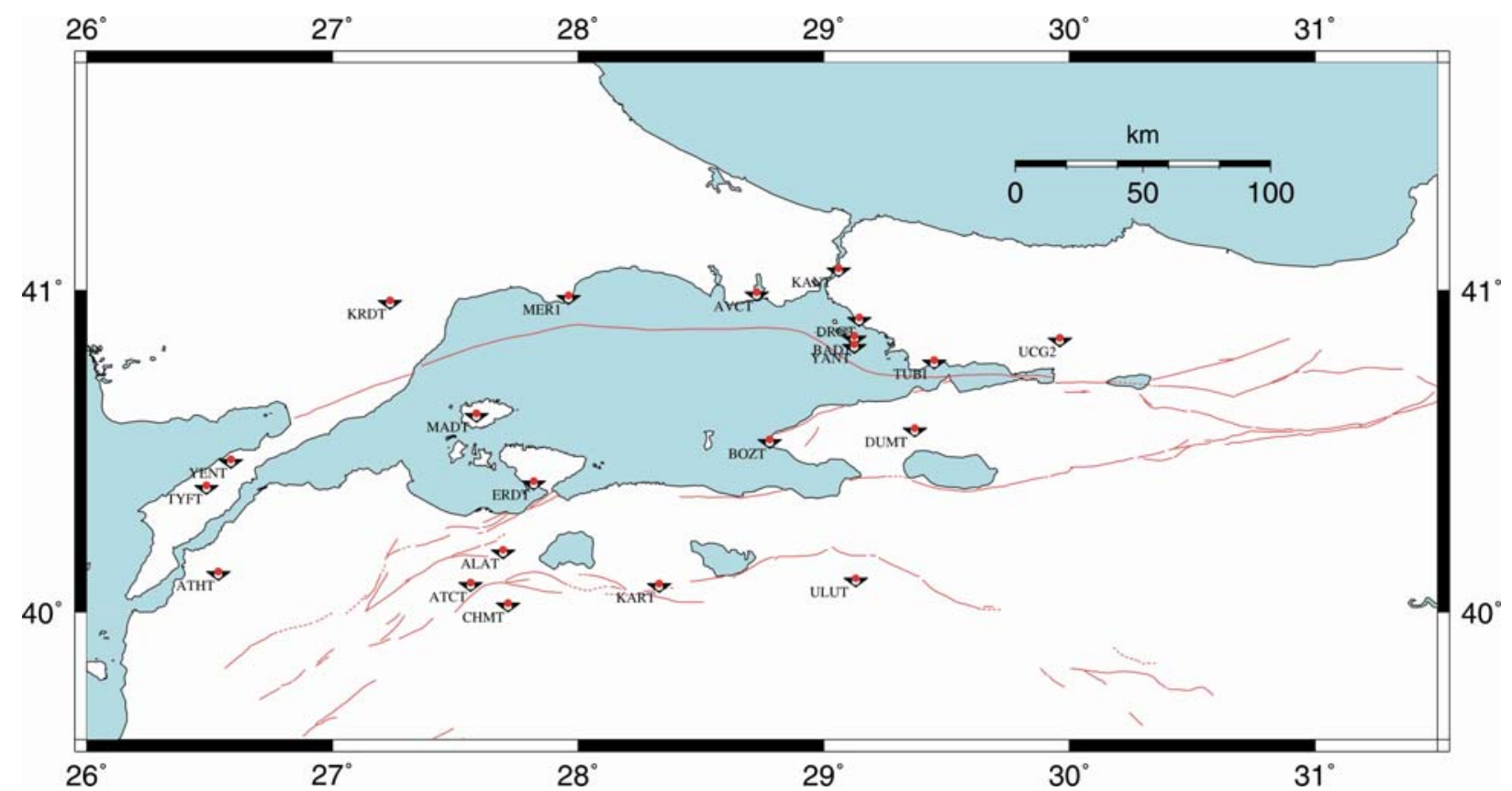

One of these points, called KANT, is located at the Kandilli Campus of Bogazici University. KANT has been collecting data since July 6, 1999. GPS data is recorded 24 hours a day, with a logging interval of 30 seconds and the elevation mask is 10 degree. Figure 2 shows the GPS sensor (Trimble 4000 SSE with a choke-ring model antenna).

Unfortunately, it cannot be said that spatially dense GPS data are available for many regions of the country. In order to come up with a solution to the related shortcoming, a national project abbreviated as CORS-TR (Continuously Operating Reference Stations Project for Turkey) [3] has been initiated. Within the scope of the mentioned project, 150 continuously operating GPS stations are being installed. According to the project schedule, GPS sensors are to be located scattered over the entire terrain of the country with a station spacing of 80-90 km (Figure 3). Therefore, the data generated will provide significant challenges to tectonic studies in Turkey. This project is being conducted by Istanbul Kultur University. 
Figure 2. GPS sensor named KANT functioning 24 hours/day (Trimble 4000 SSE with a choke-ring model antenna).

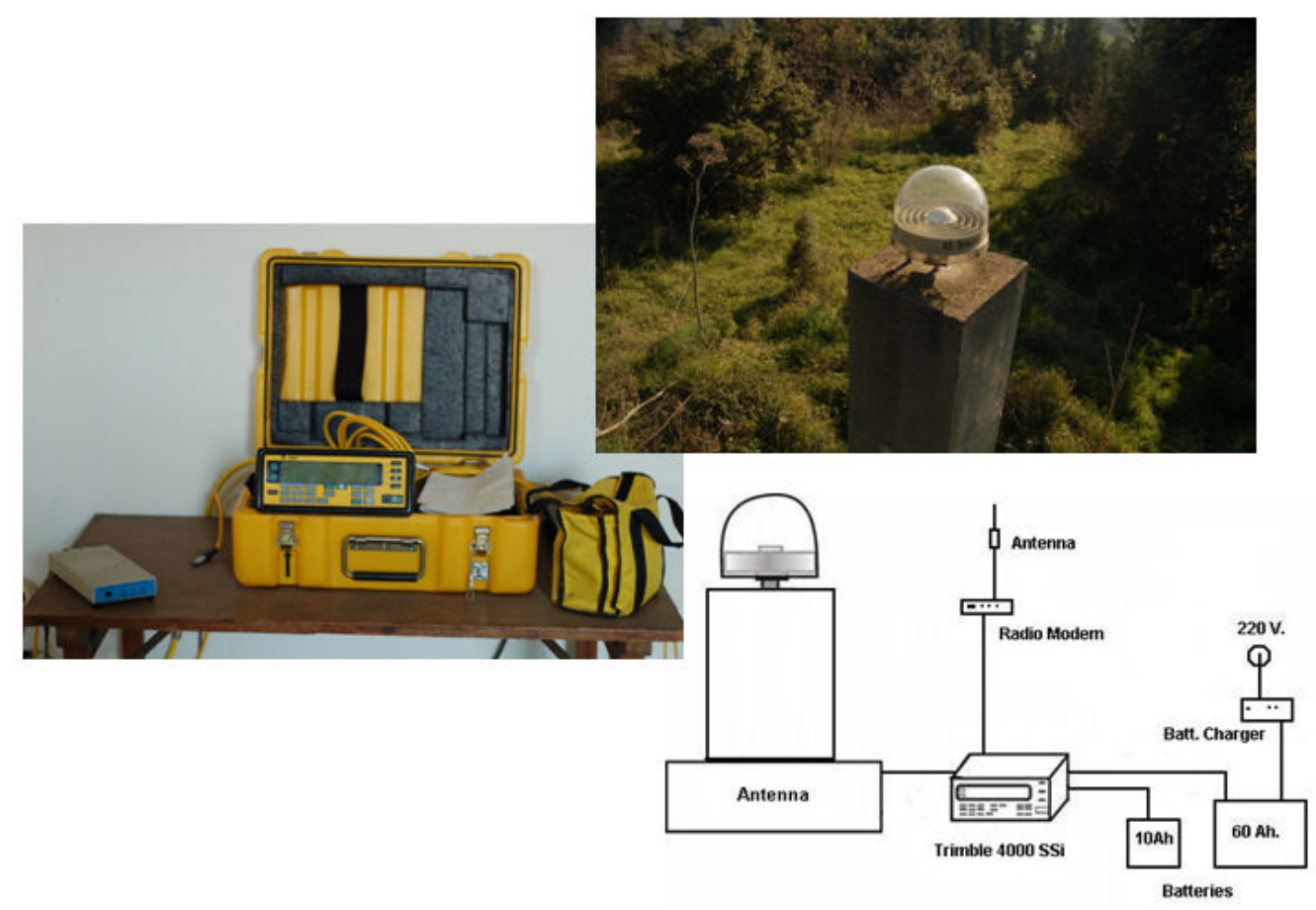

Figure 3. Locations of CORS-TR project GPS stations [3].

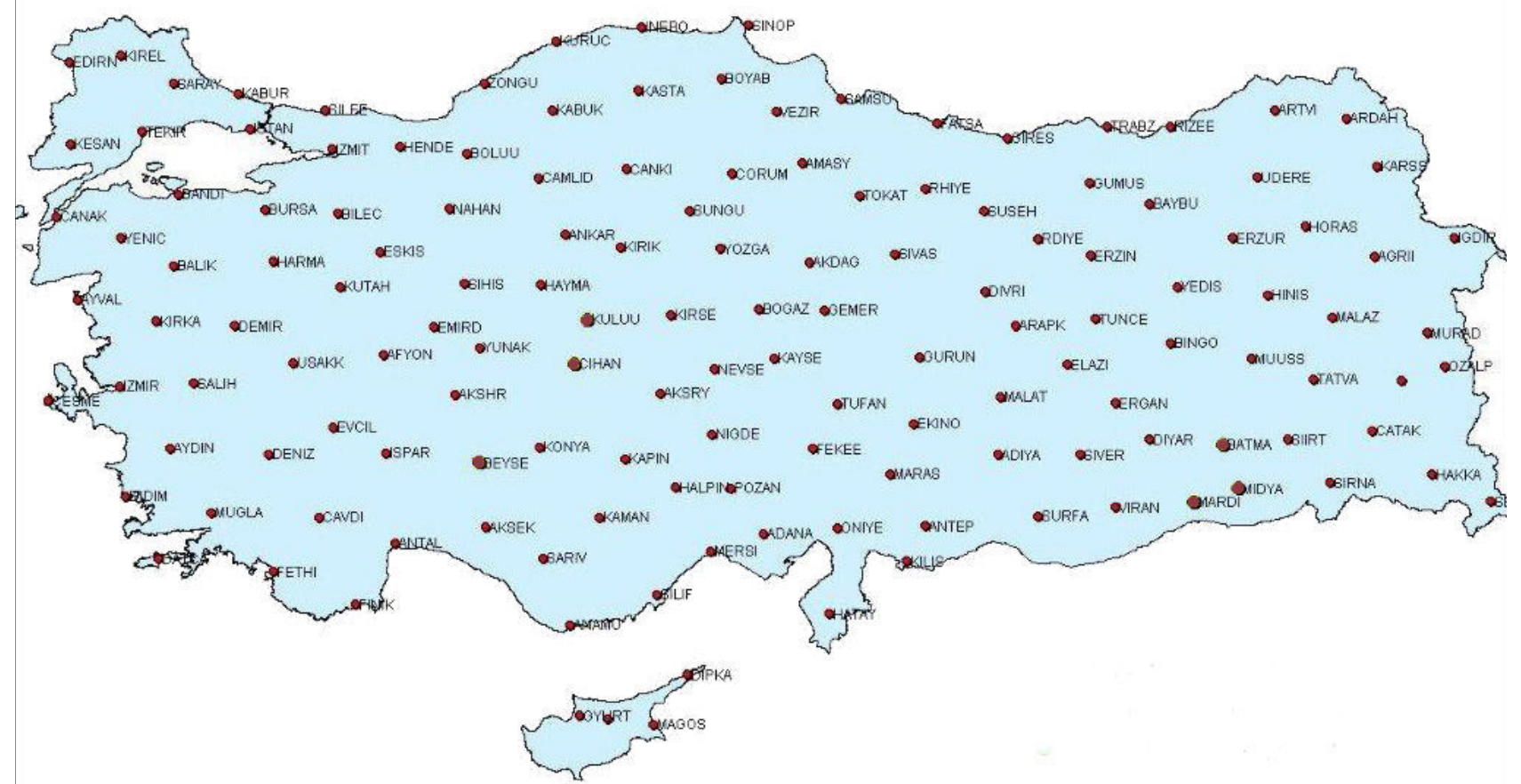

Geodetic velocity products are continuously produced by processing the continuous data from the GPS sensors. However, an automatic GPS processor is required to provide data for analyzing strain, which is the next step in earthquake research. There is an ongoing study by the Geodesy Department of 
KOERI to develop a system which is capable of visualizing strain and velocity maps using continuous data and a processor. The data transfer and processing model of the system is shown in Figure 4. Currently, online data from the KANT continuous station is being processed. After the production of GPS velocities, this data is processed for the strain assessment using the system. Using the data gathered by the campaign-based stations, the system computerizes the strain rates and velocity field maps which are to be the input information for the hazard estimation. However, the temporal resolutions of the data provided by the continuous GPS stations and the campaign-based GPS stations is not the same, and different data collection strategies require separate computation methods. A continuous strain map is estimated from the permanent station data, whereas semiannual or annual strain maps are produced from the campaign-based data, depending on the data collection intervals.

Figure 4. Data transfer and processing model.

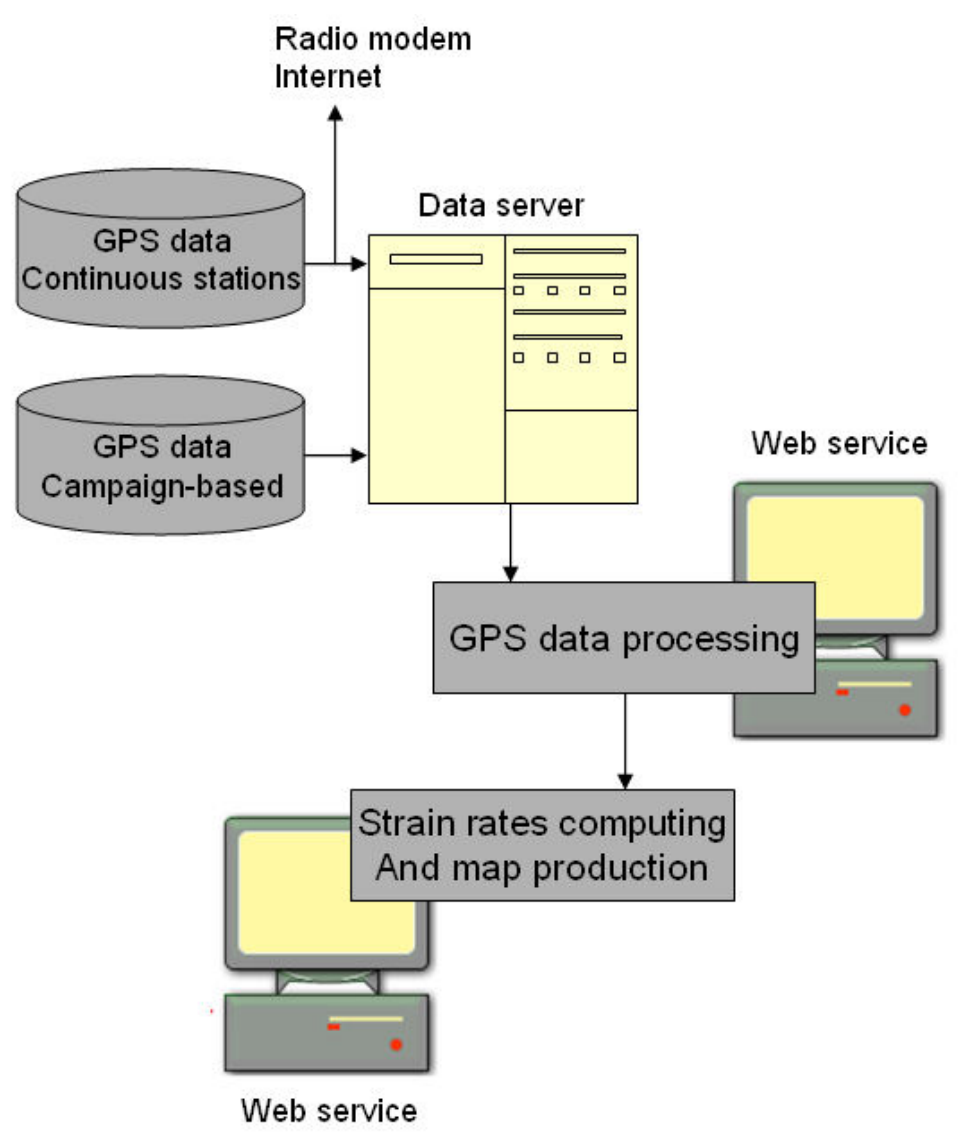

The confluence of the rapidly expanding sensor, computation, and telecommunication industries has allowed for a new instrument concept: the Sensor Web [4]. Sensor Web is a special type of webcentric information system for collecting, modeling, and storing, retrieving, sharing, manipulating, analyzing, and visualizing information of sensors, sensor observations, and associated phenomena [5]. Sensor Web was conceived at the NASA/Jet Propulsion Laboratory in 1997 and the purpose is to extract knowledge from the data. In the future, using sensor web technology, data can be collected from GPS sensor networks and archived, then position information can be produced and used for fully automated visualization of deformation for earthquake research. 


\section{Case Study: Seismic Hazard Assessment by Strain Using Continuous GPS Data}

The North Anatolian Fault Zone (NAFZ) is one of the most seismically active faults in the world. Studies monitoring horizontal crustal movements on the western part of NAFZ were started by the Geodesy Department of Kandilli Observatory and the Earthquake Research Institute of Bogazici University in 1990. This region of the country is exposed to a high seismic hazard risk because of the region's tectonics. Three geodetic control networks were established in eastern Marmara (Iznik, Sapanca, and Akyazi regions) in order to monitor crustal displacements. The first period observations had been performed by means of terrestrial methods (theodolite and electromagnetic distance-meter instruments) and these observations had been repeated annually until 1993. Since 1994 GPS measurements have been carried out at the temporary and permanent geodetic control points in the area and the crustal movements have been monitored. In order to investigate tectonic deformation in the Marmara region, GPS campaigns have been performed every year at distributed points that spread over the region by another collaborative project among BU, MIT, TUBITAK, GCM, and ITU. This network includes selected two points from each network mentioned above. Further information about this network can be found in Ergintav et al. [2].

In the case study, the crustal strain over the crust of the Marmara region in Turkey has been investigated for seismic hazard assessment using GPS velocity data obtained from these geodetic networks. In order to expand the coverage, MAGNET stations are used in the process. 65 GPS velocities come from MAGNET and also GPS campaigns performed between the years of 2003 and 2005 in Marmara region.

There are different kinds of methods to obtain strain parameters. Geodetic methods of repeated determination of position from GPS sensors are used to obtain and monitor strain accumulation and analysis. Importantly, determination of the small regions in which the strain is assumed as homogeneous affects the results. The method which was developed by Haines and Holt [6] in order to estimate a strain rate and velocity model is followed to carry out this study. A comprehensive overview of the methodology can be found in Haines et al. [7]. In this study, the model grid is continuous in longitudinal and latitudinal directions and covers Turkey, between $30^{\circ} \mathrm{N}$ and $45^{\circ} \mathrm{S}$ and between $20^{\circ} \mathrm{W}$ and $45^{\circ} \mathrm{E}$. The model is calculated on a regular grid. Each grid area is $0.5^{\circ} \times 0.5^{\circ}$ in dimension. Various grid sizes can be examined in future work. Deforming areas are determined according to the seismicity occurrence [8-10]. In total there are 1,500 grid areas, 1,081 of which are the grid areas which cover the deforming regions of Turkey, all other areas are considered to be rigid (Eurasia, African and Arabian plates). The extent of the rigid blocks is also based on the seismicity. Any number of geodetic studies can be combined in this method. In fact, the aim of geodetic measurements by GPS sensors is the determination of position. But they also provide an indirect measure of the rate of seismic productivity of a region. And its spatial derivatives can provide details of tectonic process such as strain.

According to Haines and Holt [6], three components of strain rate tensor determine a rotation vector function $W(\hat{x})$ and it describes the horizontal velocity field $\mathrm{u}(\mathrm{r})$ expressed as:

$$
u(\hat{x})=r W(\hat{x}) \times \hat{x}
$$


where $\mathrm{r}$ is the radius of the Earth and $\hat{x}$ is the position vector on the Earth's surface. The associated horizontal components of strain rate are given by:

$$
\begin{gathered}
\varepsilon_{\phi \phi}=\frac{\Theta}{\cos \theta} \cdot \frac{\partial W}{\partial \phi}, \\
\varepsilon_{\phi \theta}=\frac{1}{2}\left(\Theta \cdot \frac{\partial W}{\partial \theta}-\frac{\Phi}{\cos \theta} \cdot \frac{\partial W}{\partial \phi}\right), \\
\varepsilon_{\theta \theta}=-\Phi \cdot \frac{\partial W}{\partial \theta}
\end{gathered}
$$

with $\phi$ and $\theta$ being longitude and latitude respectively and

$$
\begin{gathered}
\Phi=(-\sin \phi, \cos \phi, 0), \\
\Theta=(-\sin \theta \cos \phi,-\sin \theta \sin \phi, \cos \theta)
\end{gathered}
$$

being the unit vectors in the east and north directions. Any region, where W(r) is constant, is considered undeforming (rigid). The Bessel form of a bi-cubic spline interpolation is used to make strain rates continuous at the nodes of the grid. These values are obtained from the least-squares inversion between the observed and predicted values of strain rate and velocity. Figure 5 shows the velocity field representing active deformation rate from the GPS campaigns between 2003 and 2005 in the region. Figure 6 represents the strain rates map derived from this velocity field.

Figure 5. Horizontal velocity field of the Marmara Region in a Eurasia-fixed reference frame (ellipses are at 95\% confidence level and the data covers 2003-2005 time intervals).

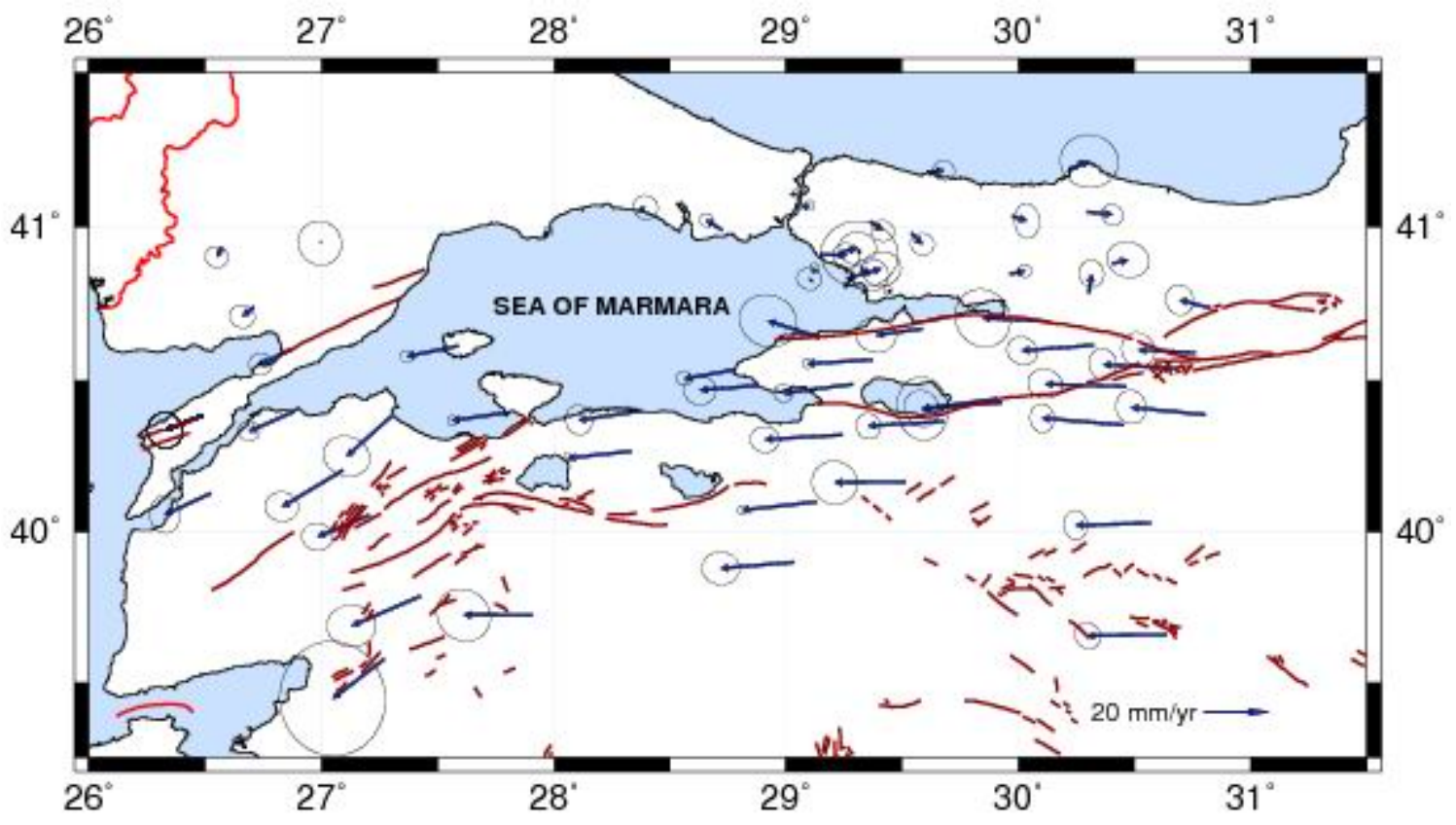


Figure 6. Principal strain rates $\left(\varepsilon_{1}\right.$ and $\left.\varepsilon_{2}\right)$ for Marmara region from the inversion of GPS velocities. Inside arrows indicate compression directions and outside arrows indicate extension directions.

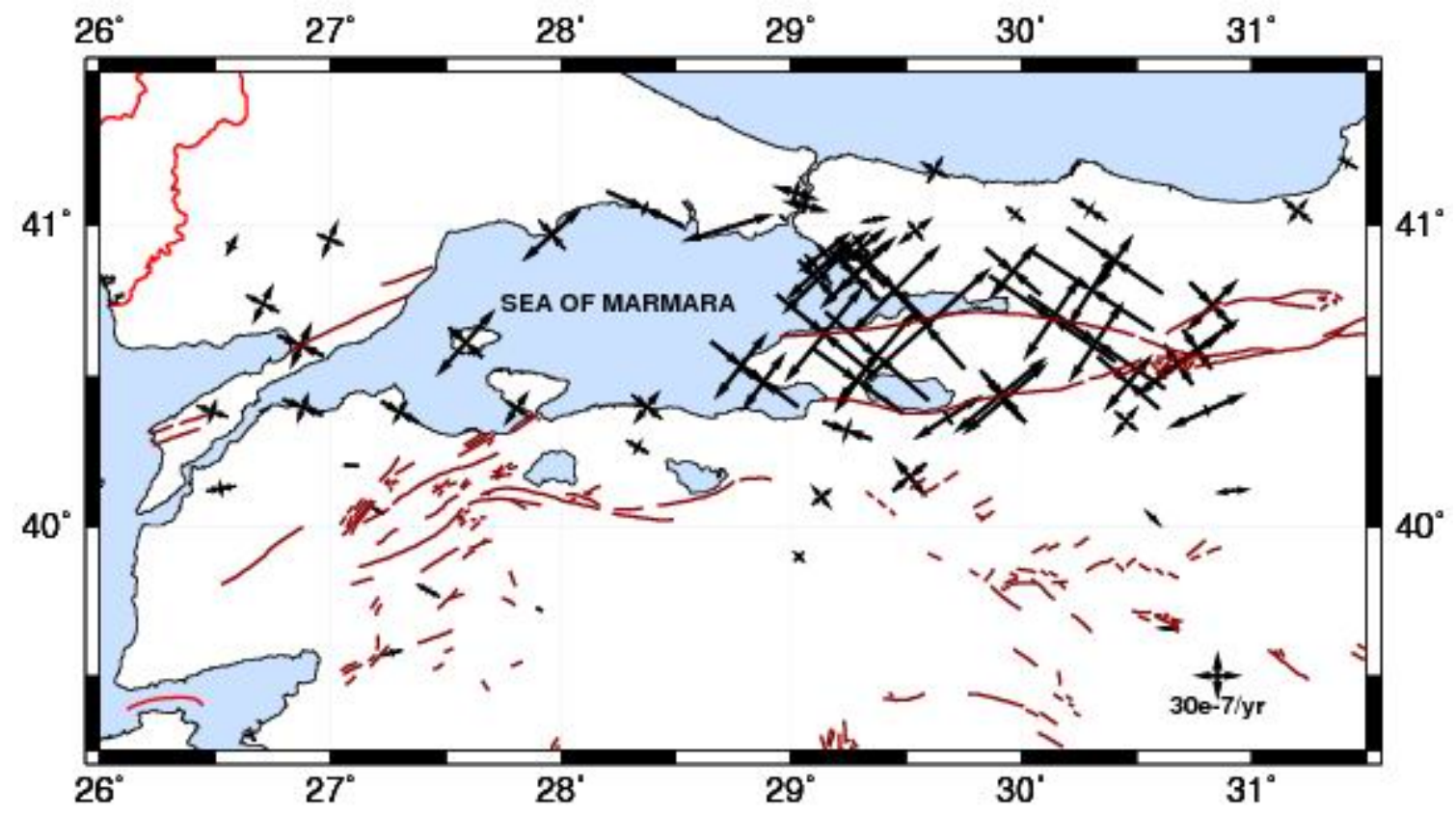

\section{Results}

Results are presented in Tables 1 and 2. They show that the east-west shortening and north-south extension of north-western Turkey are closely related to right-lateral faulting. The velocity value by the evaluation of three GPS campaigns is reaching approximately $25 \mathrm{~mm} / \mathrm{yr}$, and the minimum velocity is $0.42 \mathrm{~mm} / \mathrm{yr}$. This has an agreement with the region tectonics and the results are very close to the results obtained by Ergintav et al. [11]. As it can be seen from the Figure 5, confidence ellipses are larger than velocity vectors at the stations located on the nortern part of the study area. Stations located around south branch of western NAFZ have movements towards west and south-west directions.

Table 1. Horizontal GPS velocities of the Marmara Region in a Eurasia-fixed reference frame and 1-sigma uncertainties (plotted with 95\% confidence ellipses in Figure 1). RHO is the correlation coefficient between the $\mathrm{E}$ (east) and $\mathrm{N}$ (north) uncertainties.

\begin{tabular}{|c|c|c|c|c|c|c|c|}
\hline Site & $\begin{array}{c}\text { Longitude } \\
\left({ }^{\circ}\right) \\
\end{array}$ & $\begin{array}{c}\text { Latitude } \\
\left(^{0}\right) \\
\end{array}$ & $\begin{array}{c}E_{\text {vel }} \\
(\mathbf{m m} / \mathbf{y r})\end{array}$ & $\begin{array}{c}\mathrm{N}_{\text {vel }} \\
(\mathbf{m m} / \mathbf{y r})\end{array}$ & $\begin{array}{c}E_{\text {sig }} \\
(\mathrm{mm} / \mathbf{y r})\end{array}$ & $\begin{array}{c}\mathbf{N}_{\text {sig }} \\
(\mathbf{m m} / \mathbf{y r})\end{array}$ & RHO \\
\hline ALAP & 31.417 & 41.201 & 7.42 & 5.23 & 4.35 & 3.08 & -0.076 \\
\hline AKKO & 31.198 & 41.045 & 7.05 & 9.77 & 3.08 & 2.65 & -0.093 \\
\hline CMLN & 30.916 & 40.118 & -24.81 & 2.19 & 0.97 & 0.82 & -0.063 \\
\hline KDER & 30.827 & 40.735 & -9.62 & 2.49 & 0.94 & 0.88 & -0.067 \\
\hline TEBA & 30.804 & 40.386 & -23.00 & 2.25 & 1.07 & 0.94 & -0.052 \\
\hline
\end{tabular}


Table 1. Cont.

\begin{tabular}{|c|c|c|c|c|c|c|c|}
\hline AGOK & 30.761 & 40.589 & -17.73 & 0.78 & 1.10 & 1.05 & -0.103 \\
\hline AGUZ & 30.680 & 40.538 & -22.79 & 1.20 & 0.98 & 0.88 & -0.083 \\
\hline ESKI & 30.637 & 39.658 & -24.38 & -0.35 & 0.81 & 0.81 & -0.118 \\
\hline MHGZ & 30.570 & 40.028 & -23.34 & -0.65 & 0.91 & 0.76 & -0.048 \\
\hline DGCT & 30.462 & 40.478 & -25.01 & 0.82 & 0.93 & 1.08 & -0.073 \\
\hline SEYH & 30.453 & 40.351 & -25.32 & 2.15 & 0.90 & 0.76 & -0.051 \\
\hline CALT & 30.405 & 40.880 & 4.76 & 1.19 & 1.12 & 1.34 & -0.080 \\
\hline SEFI & 30.325 & 40.612 & -22.25 & -1.63 & 0.88 & 0.96 & -0.107 \\
\hline KAZI & 30.303 & 40.785 & 0.79 & 5.83 & 0.85 & 0.79 & -0.047 \\
\hline KANR & 30.294 & 41.048 & 7.88 & -0.81 & 0.66 & 0.67 & -0.094 \\
\hline KFKT & 30.229 & 41.187 & 5.40 & 2.48 & 1.67 & 1.83 & -0.029 \\
\hline SMAS & 30.134 & 40.690 & -20.73 & 1.08 & 1.83 & 1.75 & -0.091 \\
\hline $\mathrm{AKCO}$ & 29.973 & 41.034 & 4.48 & -1.41 & 1.10 & 0.78 & -0.056 \\
\hline UCG2 & 29.962 & 40.846 & 4.71 & 0.98 & 0.40 & 0.41 & -0.038 \\
\hline IUCK & 29.929 & 40.425 & -24.64 & -1.89 & 1.99 & 1.63 & -0.062 \\
\hline IGAZ & 29.908 & 40.438 & -23.31 & -3.09 & 1.16 & 1.10 & -0.097 \\
\hline DERB & 29.681 & 40.362 & -23.49 & -1.42 & 0.82 & 0.76 & -0.067 \\
\hline SILE & 29.623 & 41.179 & 4.04 & 0.37 & 0.63 & 0.67 & -0.063 \\
\hline OLUK & 29.585 & 40.667 & -14.29 & -1.96 & 1.10 & 1.26 & -0.061 \\
\hline OVCT & 29.539 & 40.980 & 3.41 & -3.46 & 0.68 & 0.75 & -0.038 \\
\hline HMZA & 29.514 & 40.164 & -22.00 & -0.24 & 1.37 & 1.42 & -0.029 \\
\hline TUBI & 29.451 & 40.787 & -1.15 & 0.80 & 0.29 & 0.26 & -0.037 \\
\hline DUMT & 29.372 & 40.566 & -20.16 & -1.16 & 0.32 & 0.31 & -0.039 \\
\hline KRDM & 29.362 & 41.017 & 3.79 & -2.90 & 0.67 & 0.74 & -0.057 \\
\hline IBBT & 29.321 & 40.866 & 2.82 & -2.22 & 1.02 & 1.18 & 0.014 \\
\hline HART & 29.310 & 40.927 & 0.42 & -1.60 & 2.10 & 2.43 & -0.029 \\
\hline KUTE & 29.288 & 40.485 & -21.64 & -2.77 & 0.55 & 0.59 & -0.043 \\
\hline KAMT & 29.273 & 40.834 & 9.78 & 2.75 & 1.09 & 1.23 & 0.030 \\
\hline ERCT & 29.243 & 40.319 & -24.05 & -1.44 & 0.81 & 0.91 & -0.028 \\
\hline YACT & 29.238 & 40.917 & 4.94 & 1.14 & 1.03 & 1.19 & 0.000 \\
\hline DRGT & 29.145 & 40.909 & 8.18 & -0.27 & 0.77 & 0.85 & -0.033 \\
\hline CINA & 29.143 & 40.639 & -15.87 & 5.07 & 1.66 & 1.81 & -0.091 \\
\hline ULUT & 29.131 & 40.098 & -23.02 & -2.59 & 0.30 & 0.28 & -0.041 \\
\hline BAD1 & 29.118 & 40.852 & 0.26 & 1.21 & 0.31 & 0.29 & -0.037 \\
\hline YANT & 29.113 & 40.820 & -1.05 & 0.96 & 0.70 & 0.76 & -0.050 \\
\hline KANT & 29.061 & 41.061 & 2.90 & 0.87 & 0.31 & 0.30 & -0.038 \\
\hline BLOT & 29.033 & 39.899 & -22.61 & -1.93 & 1.03 & 1.19 & -0.021 \\
\hline ISTA & 29.019 & 41.104 & 1.84 & 0.35 & 0.29 & 0.27 & -0.037 \\
\hline FIST & 28.882 & 40.481 & -18.27 & -1.47 & 0.92 & 1.01 & -0.014 \\
\hline BOZT & 28.782 & 40.534 & -15.92 & -2.82 & 0.46 & 0.48 & -0.042 \\
\hline
\end{tabular}


Table 1. Cont.

\begin{tabular}{lrrrrrrr}
\hline AVCT & 28.724 & 40.989 & -4.900 & 3.10 & 0.41 & 0.42 & -0.053 \\
YENN & 28.373 & 40.398 & -19.10 & -2.82 & 0.93 & 0.85 & -0.069 \\
SELP & 28.365 & 41.052 & 2.09 & 1.01 & 0.75 & 0.76 & -0.051 \\
KART & 28.333 & 40.265 & -19.73 & -2.10 & 0.28 & 0.26 & -0.043 \\
MER1 & 27.962 & 40.967 & 1.07 & 1.88 & 0.29 & 0.26 & -0.035 \\
BALI & 27.906 & 39.722 & -21.20 & 0.08 & 1.65 & 1.69 & -0.104 \\
ERDT & 27.808 & 40.393 & -17.65 & -2.56 & 0.31 & 0.30 & -0.043 \\
MADT & 27.587 & 40.611 & -15.91 & -3.29 & 0.37 & 0.38 & -0.036 \\
ALAN & 27.424 & 39.785 & -21.26 & -9.15 & 1.31 & 1.54 & -0.013 \\
KABI & 27.301 & 40.381 & -13.88 & -12.43 & 1.28 & 1.45 & -0.106 \\
EGMI & 27.269 & 39.577 & -15.95 & -12.24 & 3.61 & 3.33 & -0.020 \\
ASMT & 27.204 & 40.054 & -16.01 & -6.70 & 0.87 & 0.97 & -0.046 \\
BKCT & 27.091 & 40.203 & -18.83 & -11.33 & 0.93 & 1.05 & -0.037 \\
KRDT & 26.999 & 40.951 & -0.44 & -0.37 & 1.39 & 1.37 & -0.051 \\
SEVK & 26.880 & 40.396 & -13.90 & -6.14 & 0.61 & 0.67 & -0.029 \\
KVAK & 26.871 & 40.601 & -9.59 & -4.65 & 0.69 & 0.73 & -0.004 \\
DOKU & 26.706 & 40.739 & -3.45 & -3.01 & 0.71 & 0.80 & -0.048 \\
BGNT & 26.570 & 40.932 & -1.56 & -2.86 & 0.66 & 0.72 & -0.037 \\
ATHT & 26.524 & 40.126 & -14.28 & -6.59 & 1.17 & 0.96 & -0.042 \\
TYFT & 26.487 & 40.383 & -11.54 & -4.66 & 1.12 & 1.10 & -0.050 \\
\hline
\end{tabular}

Trimble 4000 SSI and 4000 SSE GPS receivers were used to obtain geodetic data. 10-hour/day observation was realized at each campaign-based station. The elevation mask was $10^{\circ}$ and the logging interval was 30 seconds. The processing and evaluation of the GPS campaigns was performed with the GAMIT [12] / GLOBK [13] software package. Each campaign were processed using the International Terrestrial Reference Frame; the ITRF2000. Precise orbit by International GPS Service (IGS) was obtained in SP3 (Standard Product 3) format from SOPAC (Scripps Orbit and Permanent Array Center). Earth Rotation Parameters (ERP) came from USNO_bull_b (United States Naval Observatory_bulletin_b). 9-parameter Berne model was used for the effects of the radiation and the pressure. Scherneck model (IERS standards, 1992) was used for the ocean tide loading effect. Zenith Delay unknowns were computed based on the Saastamoinen a priori standard troposphere model with 2-hour interval. Iono-free LC (L3) linear combination of L1\&L2 carrier phases was used. The model which depended on the height was preferred for the phase centers of the antennas. Loosely-constrained daily solutions obtained from GAMIT were included in the ITRF2000 reference frame by 7 parameters (3 offset-3 rotation-1 scale) transformation with 10 global IGS stations (Table 2). 
Table 2. Principal strains computed at GPS sites.

\begin{tabular}{|c|c|c|c|c|c|}
\hline Site & $\begin{array}{c}\text { Longitude } \\
\left({ }^{0}\right) \\
\end{array}$ & $\begin{array}{c}\text { Latitude } \\
\left(^{0}\right) \\
\end{array}$ & $\varepsilon_{1}\left(10^{-7}\right.$ year $\left.^{-1}\right)$ & $\varepsilon_{2}\left(10^{-7}\right.$ year $\left.^{-1}\right)$ & Azimuth $\left({ }^{0}\right)$ \\
\hline ALAP & 31.417 & 41.201 & 0.20 & -0.47 & 27.579 \\
\hline AKKO & 31.198 & 41.045 & 0.63 & -0.81 & 39.005 \\
\hline CMLN & 30.916 & 40.118 & 0.69 & -0.03 & 83.628 \\
\hline KDER & 30.827 & 40.735 & 1.59 & -1.46 & 45.174 \\
\hline TEBA & 30.804 & 40.386 & 1.87 & -0.22 & 65.961 \\
\hline AGOK & 30.761 & 40.589 & 2.30 & -1.10 & 54.433 \\
\hline AGUZ & 30.680 & 40.538 & 2.35 & -1.11 & 54.292 \\
\hline ESKI & 30.637 & 39.658 & 0.42 & -0.05 & 92.415 \\
\hline MHGZ & 30.570 & 40.028 & 0.44 & -0.11 & 135.090 \\
\hline DGCT & 30.462 & 40.478 & 1.61 & -1.86 & 40.386 \\
\hline SEYH & 30.453 & 40.351 & 0.80 & -0.64 & 39.668 \\
\hline CALT & 30.405 & 40.880 & 1.39 & -2.67 & 34.398 \\
\hline SEFI & 30.325 & 40.612 & 2.16 & -3.84 & 34.155 \\
\hline KAZI & 30.303 & 40.785 & 1.88 & -3.45 & 32.962 \\
\hline KANR & 30.294 & 41.048 & 0.26 & -0.94 & 32.693 \\
\hline KFKT & 30.229 & 41.187 & 0.04 & -0.39 & 120.274 \\
\hline SMAS & 30.134 & 40.690 & 2.22 & -3.52 & 34.370 \\
\hline $\mathrm{AKCO}$ & 29.973 & 41.034 & 0.22 & -0.51 & 39.173 \\
\hline UCG2 & 29.962 & 40.846 & 1.58 & -1.67 & 40.637 \\
\hline IUCK & 29.929 & 40.425 & 2.46 & -1.44 & 49.743 \\
\hline IGAZ & 29.908 & 40.438 & 2.66 & -1.44 & 50.756 \\
\hline DERB & 29.681 & 40.362 & 1.78 & -0.36 & 57.058 \\
\hline SILE & 29.623 & 41.179 & 0.69 & -0.65 & 119.909 \\
\hline OLUK & 29.585 & 40.667 & 3.92 & -2.68 & 48.165 \\
\hline OVCT & 29.539 & 40.980 & 0.90 & -0.53 & 52.214 \\
\hline HMZA & 29.514 & 40.164 & 1.06 & -0.97 & 139.743 \\
\hline TUBI & 29.451 & 40.787 & 2.82 & -2.39 & 45.442 \\
\hline DUMT & 29.372 & 40.566 & 2.75 & -3.14 & 40.885 \\
\hline KRDM & 29.362 & 41.017 & 0.58 & -0.11 & 79.503 \\
\hline IBBT & 29.321 & 40.866 & 1.87 & -1.35 & 46.916 \\
\hline HART & 29.310 & 40.927 & 12.71 & -0.66 & 51.748 \\
\hline KUTE & 29.288 & 40.485 & 1.72 & -2.61 & 35.832 \\
\hline KAMT & 29.273 & 40.834 & 2.10 & -1.57 & 45.480 \\
\hline ERCT & 29.243 & 40.319 & 0.45 & -1.18 & 19.518 \\
\hline YACT & 29.238 & 40.917 & 1.33 & -0.59 & 52.017 \\
\hline DRGT & 29.145 & 40.909 & 1.43 & -0.45 & 52.840 \\
\hline CINA & 29.143 & 40.639 & 2.76 & -2.86 & 39.432 \\
\hline ULUT & 29.131 & 40.098 & 0.63 & -0.53 & 140.454 \\
\hline
\end{tabular}


Table 2. Cont.

\begin{tabular}{|c|c|c|c|c|c|}
\hline BAD1 & 29.118 & 40.852 & 1.92 & -0.91 & 47.284 \\
\hline YANT & 29.113 & 40.820 & 2.16 & -1.22 & 45.343 \\
\hline KANT & 29.061 & 41.061 & 1.00 & -0.33 & 103.166 \\
\hline BLOT & 29.033 & 39.899 & 0.30 & -0.27 & 134.063 \\
\hline ISTA & 29.019 & 41.104 & 1.00 & -0.52 & 107.245 \\
\hline FIST & 28.882 & 40.481 & 1.59 & -1.95 & 36.827 \\
\hline BOZT & 28.782 & 40.534 & 1.85 & -1.78 & 38.365 \\
\hline AVCT & 28.724 & 40.989 & 2.09 & 0.09 & 73.382 \\
\hline YENN & 28.373 & 40.398 & 0.89 & -0.87 & 38.472 \\
\hline SELP & 28.365 & 41.052 & 0.29 & -1.92 & 24.344 \\
\hline KART & 28.333 & 40.265 & 0.32 & -0.56 & 29.569 \\
\hline MER1 & 27.962 & 40.967 & 1.74 & -0.89 & 48.025 \\
\hline BALI & 27.906 & 39.722 & 0.07 & -0.13 & 31.147 \\
\hline ERDT & 27.808 & 40.393 & 0.88 & -0.58 & 35.586 \\
\hline MADT & 27.587 & 40.611 & 1.94 & -1.01 & 41.376 \\
\hline ALAN & 27.424 & 39.785 & 0.11 & -0.59 & 29.485 \\
\hline KABI & 27.301 & 40.381 & 0.53 & -0.96 & 30.775 \\
\hline EGMI & 27.269 & 39.577 & -0.15 & -0.45 & 166.474 \\
\hline ASMT & 27.204 & 40.054 & -0.07 & -0.31 & 25.166 \\
\hline BKCT & 27.091 & 40.203 & 0.03 & -0.31 & 1.916 \\
\hline KRDT & 26.999 & 40.951 & 0.85 & -0.62 & 22.674 \\
\hline SEVK & 26.880 & 40.396 & 0.66 & -0.97 & 20.530 \\
\hline KVAK & 26.871 & 40.601 & 1.06 & -1.17 & 24.678 \\
\hline DOKU & 26.706 & 40.739 & 0.92 & -0.83 & 27.207 \\
\hline BGNT & 26.570 & 40.932 & 0.49 & -0.24 & 27.546 \\
\hline ATHT & 26.524 & 40.126 & 0.30 & -0.67 & 169.609 \\
\hline TYFT & 26.487 & 40.383 & 0.50 & -0.75 & 18.871 \\
\hline
\end{tabular}

A present-day deformation field is obtained by GPS velocities in western NAFZ. As it is shown in Figure 6, north-south extension is dominant in Marmara region.

\section{Discussion}

Scientific understanding of earthquakes is vital. Seismic hazard analysis can be defined as the integration of geophysical, geological, and geodetic data to estimate earthquake potential. If the seismic properties of the faults can be analyzed benefiting from data with high spatial and temporal resolution, then earthquake losses can be reduced. As the population increases, urban development and construction work expand on areas susceptible to earthquakes. With a greater understanding of the causes and effects of earthquakes, it may be possible to reduce the damage and loss of life from these destructive phenomena. Continuous and accurate information of relative position is very important for 
the analysis of crustal deformation and for making long-term earthquake predictions. GPS sensors are tools which can provide this kind of information.

Assessment of strain accumulation throughout Turkey or in specifically targeted areas can be obtained using geodetic data from GPS sensors. Determination of strain accumulation can identify areas of high seismic hazard in Turkey. In order to improve the understanding of the relationship between strain accumulation and seismic hazard assessment, integration of geodetically derived data from regional and national networks with the existing seismic catalog is needed. While GPS measurements indicate elastic deformation for a region, seismicity provides information about the permanent deformation. Seismic data for all Turkey is available, especially since 1970. Furthermore, focal mechanisms are available from both Global CMT catalog [9] and National Earthquake Monitoring Center (NEMC) of KOERI [10]. These data can then be used also to obtain strain and velocity maps.

From the results of this study, we can conclude that the losses of life and property due to earthquake activity in Turkey seem to be unavoidable. However, their magnitude can be reduced. The geodetic deformation field is dominated by right-lateral strike-slip deformation along NAFZ. And western NAFZ where has large urban and industrial centers has the potential for large earthquakes. The eastern NAFZ is also capable of generating major earthquakes in every 3-4 years. To conclude, there is an exigency for a system which will have the ability to computerize earthquake hazard maps as quickly as possible to provide information for making decisions on risk assessments and emergency managements.

\section{Acknowledgements}

The authors thank colleagues from the Geodesy Department and also the Directorate of Kandilli Observatory and Earthquake Research Institute of Bogazici University. They would also like to thank Marmara Research Center of TUBITAK. This study was supported by the Scientific Research Projects Fund of Bogazici University under Grant No 04T301.

\section{References and Notes}

1. United Nations Development Programme Home Page. http://www.undp.org (accessed January 22, 2008).

2. Ergintav, S.; Burgmann, R.; McClusky, S.; Cakmak, R.; Reilinger, R.; Lenk, O.; Barka, A.; Ozener, H. Postseismic Deformation Near the Izmit Earthquake (08/17/1999, M = 7.5) Rupture Zone. Bull. Seismol. Soc. Amer. 2002, 92, 194-207.

3. Uzel, T. and Eren, K. CORS-TR Project (Summary): Establishment of International CORS System and Determination of Datum Transformation Parameters. Istanbul Kultur University. http://cors-tr.iku.edu.tr (accessed January 23, 2008).

4. Delin, K.A. The Sensor Web: A Macro-Instrument for Coordinated Sensing. Sensors 2002, 2, 270-285.

5. Sensor Web at Geomatics University of Calgary Home Page. http://sensorweb.geomatics. ucalgary.ca (accessed February 4, 2008). 
6. Haines, A.J.; Holt, W.E. A Procedure to Obtain the Complete Horizontal Motions Within Zones of Distributed Deformation From the Inversion of Strain Rate Data. J. Geophys. Res. 1993, 98, 12057-12082.

7. Haines, A.J.; Jackson, J.A.; Holt, W.E.; Agnew, D.C. Representing Distributed Deformation by Continuous Velocity Field, Institute of Geological \& Nuclear Sciences: Wellington, New Zealand, 1998; Volume 5, pp. 1-121.

8. Ambraseys, N.N.; Finkel, C.F. The Seismicity of Turkey and Adjacent Areas, A Historical Review, Eren: Istanbul, Turkey, 1995; pp. 1500-1800.

9. Global CMT Web Page; http://www.globalcmt.org (accessed January 23, 2008).

10. KOERI Earthquake Catalog, Bogazici University, Kandilli Observatory and Earthquake Research Institute, National Earthquake Monitoring Center, Waveform Data Request System, May 2006; http://barbar.koeri.boun.edu.tr/sismo/zKDRS/bilgi.htm (accessed January 23, 2008).

11. Ergintav, S.; Dogan, U.; Gerstenecker, C.; Cakmak, R.; Belgen, A.; Demirel, H.; Aydin, C.; Reilinger, R. A Snapshot (2003-2005) of the 3D Postseismic Deformation for the 1999, Mw $=7.4$ Izmit Earthquake in the Marmara Region, Turkey, by First Results of Joint Gravity and GPS Monitoring. J. Geodynamics 2007, 44, 1-18.

12. King, R.W.; Bock, Y. Documentation for the GAMIT GPS Analysis Software. Massachusetts Institute of Technology: Cambridge, MA, USA, 2004.

13. Herring, T.A. GLOBK Global Kalman Filter VLBI and GPS Analysis Program. Massachusetts Institute of Technology: Cambridge, MA, USA, 2004.

(C) 2009 by the authors; licensee Molecular Diversity Preservation International, Basel, Switzerland. This article is an open-access article distributed under the terms and conditions of the Creative Commons Attribution license (http://creativecommons.org/licenses/by/3.0/). 